organic matter in the soil ; it has well been compared with that of the open sea.

It should be the object of those who go to Egypt for the benefit of their health to breathe as much of the air of the desert as possible, and it is unfortunate that this cannot at present be obtained in the places of residence which afford the greatest facilities and comforts for invalids. Cairo is situated on its edge, but the hotels, and all the modern town in fact, are built on low ground, which, until reclaimed artificially, was subject to the overflow, and have the whole of the ancient city, with its crowded population and impure streets, between them and the desert. Moreover, the prevailing winds, being from the north, blow directly across the delta. This and the great amount of dust, not of the cleanest kind, which fills the air of a great city full of people and animals, form the principal drawbacks to Cairo as a residence for invalids. What is greatly wanted is a place where good accommodation and comfort, combined with moderate expense, could be obtained a few miles out of Cairo, somewhere on the Mokattan Hills.

The nearest approach to this is the establishment which has just been opened at Helwân, or "Helouan-les-Bains" (as it is spelt in French), about fifteen miles south of Cairo, and three from the east bank of the river. The origin of this place was a spring of warm sulphurous water, similar in composition to that of Aix-les-Bains, in Savoy. Baths were erected here a few years ago for the use of the Khedive and his family. These have lately been considerably enlarged; and Dr. Reil, a German physician, who has lived some years in Cairo, and who speaks English well, has been appointed resident director of the establishment. Two hotels or boarding-houses, though not quite completed, had just been opened when I visited the place in January last. By next season, it will all be in good working order, and several hundred visitors will be accommodated at more reasonable prices than in Cairo.

The situation was determined by the mineral spring, which wells up in the middle of a flat sandy plain, about midway between the river and the range of rocky hills that flank the Nile valley on the east. Although not so agreeable as if higher on the hill-side, it is well within the border of the desert and fairly above the river-level.

Apart from the peculiar medicinal virtues of the waters (which are especially recommended in case of chronic rheumatic, cutaneous, and hepatic diseases), a residence at Helwân would probably be better, in a sanitary point of view, than in the hotels of Cairo; the air is purer and the life quieter ; but, for those who have not plenty of resources within themselves, it will scarcely offer the same attractions. At present, it is rather difficult of access, but the road will probably be improved before next winter.

The only other places where European travellers could pass the winter in Egypt (apart from the Nile boat, to be spoken of in the next article) are Suez and Ismailia. There are hotels at both, but of neither of them can I say anything from personal knowledge. Ismailia is a new place on the side of the Suez Canal, and has some pretty gardens on land reclaimed from the desert. It is reached by rail from Cairo in about nine hours. Its attractions are pure desert air and quiet, for it is quite away from all historical objects of interest. The principal outward events in life there must be the passage of vessels through the canal.

[To be continued.]

\section{A CASE OF PECULIAR INJURY OF THE SHOULDER-JOINT.}

By J. J. CHARLES, M.A., M.D., M.Ch., etc., Demonstrator of Anatomy, Queen's College, Belfast.

IN March last, there came under my notice a rare form of fracture of the humerus, which I believe of sufficient interest for publication. A. B., a house-porter, 30 years of age, strong and healthy, while crossing the street with a hand-cart, was knocked down by a tram-car in January 1873. The patient can give no satisfactory account of the precise way in which he received the injury, but it appears that the pole of the tram-car struck him about the middle of the left shoulder. It is unnecessary to enter into particulars regarding the different plans of treatment to which the unfortunate man was subjected at different timessuffice it to say, that pulleys and other appliances were frequently employed in the vain attempt to reduce what was believed to be a dislocation of the humerus on the dorsum scapula. It was fourteen months after the accident that my attention was directed to the case.

On examination, I found that the shoulder had lost its natural roundness and fulness, from the deltoid muscle having become flattened; that the acromion process was very prominent; and that the breadth of the articulation was greatly increased. Beneath the outer part of the spine of the scapula was an osseous tumour of the size of a small orange; its superficial surface was more or less rounded, except in front, where it was bounded by a nearly straight border that ran obliquely downwards and forwards into a long, narrow, bony process. This process could be traced downwards and forwards towards the shaft of the humerus, to which it was joined at an acute angle two or three inches below the glenoid fossa ; but it was almost impossible to determine with any degree of exactitude either the mode or the point of attachment, owing to the thickness of the soft parts covering the joint. Any doubt, however, as to the existence of this union was at once set aside on rotating the arm, as the tumour could then be both seen and felt moving along with the humerus, though it could scarcely be moved at all by the fingers applied directly. During these movements, the under surface of the tumour could be felt to be more or less flattened. The coracoid process was unusually prominent and appeared enlarged, and beneath it was a slight projection formed by the inner part of the upper end of the

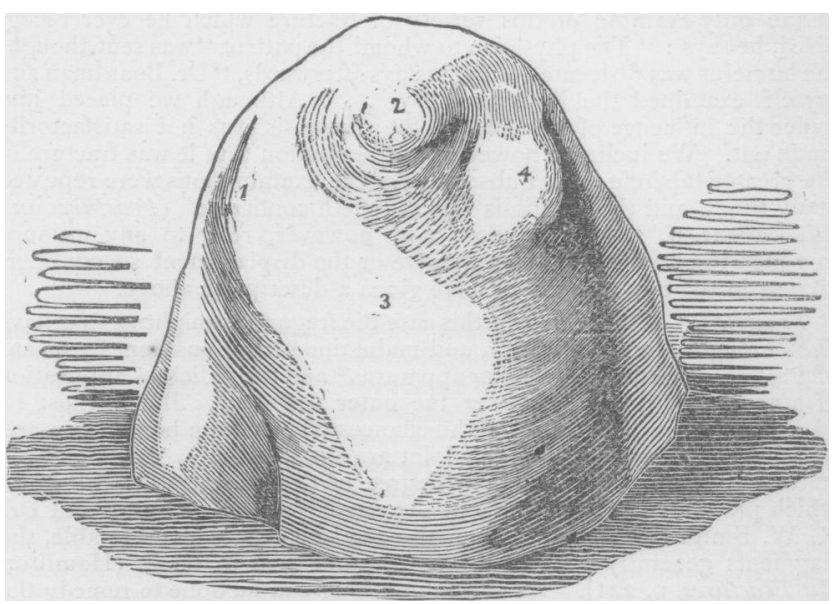

r. Prominence below Coracoid Process. r. Prominence below Coracoid Proc
2. Prominent Acromion Process. 3. F lattened Outer Surface of Shoulder . Osseous Tumour on Dorsum Scapula. pain ; but it was clear that the greater portion of it was occupied by the upper extremity of the shaft of the humerus. Between this projection under the coracoid and the tumour on the scapula was a deep sulcus, into which the finger could be readily sunk. When the elbow was held close to the side, and the fingers of both hands placed in the axilla, the upper end of the humerus could be pressed outwards as far as the lower border of the acromion process, and then the shoulder was made to assume more of its natural contour. The elbow generally lay separated from the side, but could easily be brought into contact with it. The axis of the humerus was directed upwards and inwards towards the coracoid process, and the arm was nearly half an inch shorter than its fellow of the opposite side. The "under movements" of the limb had not been interfered with; but the patient was unable to place his hand on the opposite shoulder, or to raise his arm more than six or eight inches, unless he supported it with his right hand, though he could now move it more freely than he did some time before. The arm, however, could be forcibly elevated by another person, but abduction and extension (backwards) were decidedly the most limited of all the movements. He complained of pain along the inside of his arm, and occasionally of numbness and coldness of his hand.

Diagnosis. - The tumour on the scapula was manifestly too small to consist of the whole of the head of the humerus. I, therefore, regarded it as constituted by the portion of the upper end of the bone outside the bicipital groove; and, as it was attached to the shaft of the humerus, its direction was necessarily oblique-hence its anterior border, which was formed by the outer bicipital ridge, was directed downwards and forwards, as I have described above. The manner in which the accident occurred was most probably this : the pole of the tram-car struck the upper end of the humerus near the bicipital groove, and fractured it longitudinally into two pieces, which were driven with violence-one backwards on the scapula and the other a little inwards under the coracoid process ; and in these positions they were, no doubt, maintained chiefly by the action of the external and internal rotator muscles respectively. The small amount of shortening observable at present may be due to the upper end of the bone having been displaced forwards and inwards after the outer and greater portion of the head had been broken off. 
Whether the inner fragment, like the outar one, was separated from the shaft, I could not be certain ; but, if it were, the displacement could not have been great. On this supposition, the upper end of the shaft of the bone would occupy the glenoil fossa, and the inner tuberosity with a portion of the shaft form the projection beneath the coracoid ; while the shortening of the arm would $b$ z accounted for by the shaft overlapping the fragments. On this point, however, there must still exist some doubt, unless it be cleared up in future by a post mortem examination.

Dr. Robert WV. Smith describes a few cases of "fractures of the greater tuberosity of the humerus" (Fractures and Dislocations, p. 176), which in many respects resemble the case under consideration; but, in the present instance, the amount of injury done was greater and the fracture more extensive.

Dr. Hamilton, in his account of "longitudinal fractures of the head and neck" of the humerus, alludes to the great difficulty sometimes experienced in arriving at a correct diagnosis. In relating the particulars of the only example of this variety of fracture which he ever recognised, he says : "The physician to whom" the patient "was sent thought the humerus was dislocated". Eight days afterwards, "Dr. Boardman and myself examined the limb carefully. ... Although we placed him under the influence of chloroform, the diagnosis was not satisfactorily made out. We inclined, however, to the opinion that it was fracture of the greater tubercle. ... Subsequently, the examinations were repeated many times, and the diagnosis was at length confirmed" (Fractures and Dislocations, p. 221). He does not, however, refer to any instance in which the fracture was so extensive or the displacement so considerable as in the one of which I have given a description above.

Treatment. - I think that in this case the fragments might at first have been brought almost together, and maintained in apposition by means of Professor Gordon's clavicular apparatus* and the judicious application of a properly adjusted pad over the outer fragment. But it must be admitted that in such fractures the chances of complete bony union and of freedom of movement at the joint are slight indeed. Dr. Hamilton states that union "without any degree of displacement" is a "result which probably ought never to be expected" (op. cit., p. 232); and Dr. R. W. Smith thinks that "when the displacement is considerable, the fragments generally unite by ligament rather than by bone" (Hamilton On Fractures, p. 221). At present, nothing can be done to remedy the deformity under which the patient labours ; but the amount of mobility of the joint will undoubtedly increase through time-indeed, in this respect, there has been considerable improvement already, and with this small comfort he must rest contented.

I may add that Professors Redfern and Gordon also examined this case carefully, and they arrived at almost the same conclusions as I did regarding the nature of the accident. Professor Gordon's opinion as to the relation of the inner fragment to the shaft is that which I have stated above as the second hypothesis. last.

The patient was exhibited before the Ulster Medical Society in March

\section{CASES OF CONVULSION FROM ORGANIC BRAIN-DISEASE. $\dagger$}

By W. R. GOWERS, M.D.Lond.,

Assistant-Physician to University College Hospital and to the National Hospital for the Paralysed and Epileptic.

MY object in this paper will be to lay before you the details of some convulsive seizures of local commencement and deliberate march in which there was found after death a naked-eye lesion of the brain, the position of which could be determined with accuracy. It has been shown by Dr. Hughlings Jackson t that the study of such convulsions affords one of the chief practical means of ascertaining the precise motor relations of many parts of the human brain, and of extending to it the conclusions reached by experiments on the brains of lower animals.

CASE I. Unilateral Convulsion beginning in both Frontal Musiles, in a Case of Renal Disease, with an old Hamorrhage into the opposite Cerebral Hemisphere.-A little girl, aged 8 years, was admitted into University College Hospital, under the care of Dr. Wilson Fox, on February 7th, 1874, with slight œdema of the legs and albuminuria. The dropsy had existed for two months. One day, about the time of

* This apparatus will probably be described in a short time by Professor Gordon It serves for the treatment of almost all the injuries of the shoulder-joint.

+ Read befure the Medical Section at the Annual Meeting of the British Medical

Association in Norwich, August I874.
$\ddagger$ In many places, and especially in his article on the " Localisation of Movement in the Brain". in the Lancet for January 13 th, 1873 . the commencement of the dropsy, she had been seized with severe pain in the head and vomiting ; and, next morning, a series of convulsive attacks commenced, which lasted for thirty hours, the headache and vomiting continuing for some days. A few weeks afterwards, a second similar attack occurred. On admission, the child presented no evidence of cerebral mischief; she was cheerful, quick, and there was no discoverable paralysis. The ophthalmoscope showed well marked albuminuric retinitis. One day, about a fortnight after her admission, she suddenly, without obvious cause, vomited, and, a few hours afterwards, was seized with a convulsive attack, involving the left side only. A similar attack was repeated every ten or fifteen minutes for about twelve hours, when she died, the temperature rising before death to 107.2. I was able to watch carefully several of the attacks. In the first two which I saw, the earliest spasms appeared to be at the angle of the mouth, on the left side ; but, in all that followed, this was preceded by movements in the frontal muscles; and I think it probable, therefore, that all the fits began thus, but that, in those first seen, the earliest movement was overlooked. The spasm in the frontal muscles, with which the fit commenced, was clonic, and occurred simultaneously and equally in the two frontal muscles. In a few seconds, clonic spasm set in in the orbicularis of the eyelids, on each side, but greater on the left than on the right. The left angle of the mouth was then twitched outwards, apparently by the action of the zygomatic muscles, the right side being quite motionless. Next the left arm began to jerk, apparently as a whole, and soon afterwards the left leg. The muscles passing from the limbs to the body were involved, and also the muscles of the abdomen-certainly of the left, and I thought also of the right side. No tonic spasm was observed. After lasting about a minute, the spasmodic contractions subsided, lasting longest in the zygomatic muscles and in the muscles of the left arm. When the movements were at their greatest intensity, there was a little contraction of both levatores menti; but, with the exceptions mentioned, there was no affection of muscles on the right side. I was informed that, in some of the earlier fits, there had been some jerking of the right limbs; there was none in those which I saw. During the fits, and also in the intervals between them, the eyes were directed to the right, the axes remaining parallel, and were not moved to the left. During the fit, the pupils were widely dilated.

In the intervals, there was no return to consciousness; then, in emotional movements, the right side of the face alone moved.

At the post mortem examination, there was found an old clot, apparently of at least several weeks' duration, which was situated above the right lateral ventricle, just inside the convolution of the corpus callosum, the white matter of which it involved. In size, the clot was about as large as a walnut, and its centre was about midway between the anterior and posterior extremities of the corpus callosum. The clot itself did not extend outwards beyond the middle of the roof of the ventricle, but adjacent softening reached as far as the junction of the roof and outer wall, so as to approach within one-sixth of an inch of the outer part of the corpus striatum. The softening had extended irregularly to the surface of the convolution of the corpus callosum, opposite the clot, so as to involve the grey matter at this spot. Some minute extravasations over the right parietal and occipital lobes, beneath the pia mater, constituted the only other lesion to be found in the brain. The heart was much hypertrophied. The kidneys presented extreme and old-standing disease.

REMARKS. - A convulsion affecting one-half of the body, as far as our present knowledge extends, always owns as immediate cause an organic change in one-half of the brain. As the only considerable lesion, we are justified, then, in regarding the clot as the immediate cause of the fits in this case. There was, further, that condition predisposing to convulsion which accompanies grave organic renal disease. Of the systemic influence of the renal disease, the existence of albuminuric retinitis furnished a sufficient proof. The presence, however, of this additional predisposing cause does not interfere with the interest which attaches to the character of the convulsion and to the position of the acher to as Dr. Hughlings Jackson has shown, that, in unilateral convulsions, or in general convulsions beginning unilaterally, the fit begins in the side which is first or only affected, and in some muscles on that side which are usually put into unilateral action - at the angle of the mouth, the hand, or the foot. In this case, however, the fit, which was essentially onesided, deviated from the rule, in beginning simultaneously on the two sides, that is, in the two frontal muscles; and in this deviation it is, so far as I am aware, unique. It is interesting, therefore, to observe that it began in a muscle which is rarely, if ever, put into unilateral action. Few people indeed possess the power of moving the frontal muscle on one side only without that on the other. The orbicularis of the eyelids were next involved, but less equally than the frontal mus- 